\title{
Efficacy of some variables of extraction to the total phenolic and flavonoid content in young mango (Mangifera indica L.) leaf
}

\author{
Minh Phuoc Nguyen \\ Faculty of Biotechnology, Ho Chi Minh City Open University, Ho Chi Minh City, Vietnam
}

\begin{tabular}{l} 
Article Info \\
\hline Article history \\
Received 2 February 2020 \\
Revised 19 March 2020 \\
Accepted 25 March 2020 \\
Published online 30 June 2020 \\
\hline Keywords \\
Mango leaf \\
Phenolic \\
Flavonoid \\
Extraction \\
Ethanol \\
Temperature
\end{tabular}

\begin{abstract}
Extract from mango (Mangifera indica L.) leaves has different antioxidant, anti-inflammatory and immunomodulatory properties. Tea prepared from $M$. indica leaves has a great potential as sources of mangiferin. Our research investigated the effectiveness of ethanol concentration, extraction duration and temperature to the total phenolic content (TPC) and total flavonoid content (TFC) in young mango leaves. Our results showed that all extractions had significant effect on the total phenolic content (TPC) and total flavonoid content (TFC) in this valuable herbal source. The optimal parameters were noticed at $60 \%$ ethanol for $75 \mathrm{~min}$ at $55^{\circ} \mathrm{C}$ to get the highest TPC and TFC. This finding gave a basic foundation for further experiments in production of instant soluble forms originated from this therapeutic leaf.
\end{abstract}

\section{Introduction}

Mango tree (Mangifera indica $\mathrm{L}$.) has been popularly cultivated in Vietnam. The leaves are simple alternately arranged, $15-45 \mathrm{~cm}$ in length. The phytochemical contents and medicinal values of mango (M. indica) leaves contained bioactive compounds comprising mangiferin, coumarin, sequiterpinenoids, triterpinoids, alkaloids, flavonoids, saponins, tannins and phenols (Nunez-Selles, 2005; Donatus Ebere Okwu and Vitus Ezenagu, 2008; Dhuha Alshammaa, 2016; GM Masud Parvez et al., 2016; Olasehinde et al., 2018). They were useful in vitiated conditions of cough, hiccup, hyperdipsia, burning sensation, hemorrhages, haemoptysis, haemorrhoids, wounds, ulcers, diarrhoea, dysentery, pharyngopathy, scorpion string and stomachopathy (Adesegun and Coker, 2001; Pintu and Arna Pal, 2014). The aqueous young leaves extract of $M$. indica could be utilized in the management of gastro-intestinal disorders and its effect could be potentiating as required (Pintu and Arna Pal, 2014). Natalia Medina Ramírez et al. (2016) evaluated the chemical composition of teas prepared from $M$. indica leaves, their potential use as a source of mangiferin and their total phenolic compounds. Young leaves of mango (M. indica) could be dried into herbal tea for aqueous extraction (Nguyen Phuoc Minh et al., 2018). With the pupose of utilization of phytochemical constituents

Corresponding author: Dr. Minh Phuoc Nguyen Faculty of Biotechnology, Ho Chi Minh City Open University, Ho Chi Minh City, Vietnam

E-mail: minh.np@ou.edu.vn

Tel.: +84-0947073637; +84-0984048200

Copyright (C) 2020 Ukaaz Publications. All rights reserved.

Email: ukaaz@yahoo.com; Website: www.ukaazpublications.com extracted from the young mango leaves, our present study focused on some major technical parameters influencing to the stability of antioxidant components during solvent extraction.

\section{Materials and Methods}

\subsection{Material}

Young mango leaves were collected from gardens in Tien Giang province, Vietnam. After collecting, they must be conveyed to laboratory for experiments. They were washed under tap water to remove foreign matters and dripped excess water before extraction. Chemical substances such as Folin-Ciocalteu reagent, sodium carbonate anhydrous, gallic acid, sodium nitrite, aluminium chloride, catechin were all supplied from Rainbow Trading Co. Ltd., Vietnam. UV-spectrophotometer was used for measurement.

\subsection{Researching procedure}

Young mango leaves were extracted by Soxhlet extractor with different ethanol concentrations $(50,55,60,65,70 \%)$ at different extraction time $(30,45,60,75,90,105 \mathrm{~min})$ and different extraction temperature $\left(40,45,50,55,60,65^{\circ} \mathrm{C}\right)$. The control sample was based on distilled water. The best ethanol concentration, extraction duration, extraction temperature were defined via TPC and TFC values.

\subsection{Chemical analysis}

Total phenolic content (TPC, mg GAE/100 g) was determined by the method of Li et al. (2008). Total flavonoid content (TFC, mg $\mathrm{CE} / 100 \mathrm{~g}$ ) as determined by application of a method described by Ozsoy et al. (2008). 


\subsection{Statistical analysis}

The experiments were run in triplicate with three different lots of samples. Statistical analysis was performed by the Statgraphics Centurion XVI.

\section{Results}

3.1 Effect of ethanol concentration to the stability of antioxidant components extracted from young mango leaves

Ethanol was safer, less toxic and more efficient as compared to other organic solvents. The highest significant total phenolic content (TPC, mg GAE/100 g) and total flavonoid content (TFC, mg CE/100 g) were noticed at $60 \%$ ethanol, while control treatments showed the lowest TPC and TFC (Table 1).
3.2 Effect of extraction duration to the stability of antioxidant components extracted from young mango leaves

Extraction duration is very important in decision of energy consumption and cost of the extraction assay.

The highest significant total phenolic content (TPC, mg GAE/100 g) and total flavonoid content (TFC, $\mathrm{mg} \mathrm{CE} / 100 \mathrm{~g}$ ) were noticed at 75 min, while treatments with $30 \mathrm{~min}$ showed the lowest significant TPC and TFC (Table 2).

\subsection{Effect of extraction temperature to the stability of} antioxidant components extracted from young mango leaves

The highest significant total phenolic content (TPC, mg GAE/100 g) and total flavonoid content (TFC, $\mathrm{mg} \mathrm{CE} / 100 \mathrm{~g}$ ) were noticed at $55^{\circ} \mathrm{C}$, while treatments at $40^{\circ} \mathrm{C}$ showed the lowest significant TPC and TFC (Table 3).

Table 1: Effect of ethanol concentration (\%) to TPC (mg GAE/100 g) and TFC (mg CE/100 g) extracted from young mango leaves

\begin{tabular}{|l|r|r|r|r|r|r|}
\hline Parameter & \multicolumn{6}{|c|}{ Ethanol concentration (\%) } \\
\hline & Control & 50 & 55 & 60 & 65 & 70 \\
\hline TPC (mg GAE $/ 100 \mathrm{~g})$ & $14.29 \pm 0.01^{\mathrm{d}}$ & $19.94 \pm 0.03^{\mathrm{c}}$ & $22.34 \pm 0.02^{\mathrm{bc}}$ & $27.48 \pm 0.00^{\mathrm{a}}$ & $26.03 \pm 0.02^{\mathrm{ab}}$ & $25.26 \pm 0.03^{\mathrm{b}}$ \\
TFC $(\mathrm{mg} \mathrm{CE} / 100 \mathrm{~g})$ & $3.37 \pm 0.02^{\mathrm{d}}$ & $7.42 \pm 0.00^{\mathrm{c}}$ & $8.95 \pm 0.01^{\mathrm{bc}}$ & $10.47 \pm 0.03^{\mathrm{a}}$ & $9.89 \pm 0.03^{\mathrm{ab}}$ & $9.16 \pm 0.02^{\mathrm{b}}$ \\
\hline
\end{tabular}

Note: The values were expressed as the mean of three repetitions; the same characters (denoted above), the difference between them was not significant $(\alpha=5 \%)$.

Table 2: Effect of extraction duration (min) to TPC (mg GAE/100 g) and TFC (mg CE/100 g) extracted from young mango leaves

\begin{tabular}{|l|c|c|c|c|c|c|}
\hline Parameter & \multicolumn{6}{|c|}{ Extraction duration (minutes) } \\
\hline & 30 & 45 & 60 & 75 & 90 & 105 \\
\hline TPC (mg GAE/100g) & $27.48 \pm 0.00^{\mathrm{d}}$ & $29.54 \pm 0.03^{\mathrm{cd}}$ & $31.63 \pm 0.02^{\mathrm{c}}$ & $34.57 \pm 0.01^{\mathrm{a}}$ & $33.84 \pm 0.03^{\mathrm{ab}}$ & $33.07 \pm 0.01^{\mathrm{b}}$ \\
TFC (mg CE/100g) & $10.47 \pm 0.03^{\mathrm{d}}$ & $11.04 \pm 0.01^{\mathrm{c}}$ & $11.87 \pm 0.00^{\mathrm{bc}}$ & $12.89 \pm 0.02^{\mathrm{a}}$ & $12.74 \pm 0.00^{\mathrm{ab}}$ & $12.31 \pm 0.02^{\mathrm{b}}$ \\
\hline
\end{tabular}

Note: The values were expressed as the mean of three repetitions; the same characters (denoted above), the difference between them was not significant $(\alpha=5 \%)$.

Table 3: Effect of extraction temperature $\left({ }^{\circ} \mathrm{C}\right)$ to $\mathrm{TPC}(\mathrm{mg} \mathrm{GAE} / 100 \mathrm{~g})$ and $\mathrm{TFC}(\mathrm{mg} \mathrm{CE} / 100 \mathrm{~g})$ extracted from young mango leaves

\begin{tabular}{|c|c|c|c|c|c|c|}
\hline Parameters & Extr & tion temperatu & $\left.{ }^{\circ} \mathbf{C}\right)$ & & & \\
\hline & 40 & 45 & 50 & 55 & 60 & 65 \\
\hline $\begin{array}{l}\text { TPC (mg GAE/100g) } \\
\text { TFC (mg CE } / 100 \mathrm{~g})\end{array}$ & $\begin{array}{l}34.57 \pm 0.01^{\mathrm{d}} \\
12.89 \pm 0.02^{\mathrm{c}}\end{array}$ & $\begin{array}{l}36.27 \pm 0.03^{\mathrm{cd}} \\
13.28 \pm 0.00^{\mathrm{bc}}\end{array}$ & $\begin{array}{l}37.85 \pm 0.01^{\mathrm{b}} \\
13.87 \pm 0.01^{\mathrm{ab}}\end{array}$ & $\begin{array}{l}39.71 \pm 0.02^{\mathrm{a}} \\
14.27 \pm 0.00^{\mathrm{a}}\end{array}$ & $37.14 \pm 0.03^{\text {bc }}$ & $36.85 \pm 0.00^{c}$ \\
\hline
\end{tabular}

Note: The values were expressed as the mean of three repetitions; the same characters (denoted above), the difference between them was not significant $(\alpha=5 \%)$.

\section{Discussion}

The phenolic stability from $M$. indica was investigated by various ethanol concentration $(0-100 \%, v / v)$. The optimal conditions for phenolic recovery were noticed at $40 \%$ ethanol (Chew et al., 2011). It is obviously demonstrated that the binary-solvent was more effective than the single-solvent in the phenolic extraction (Chirinos et al., 2007; Silva et al., 2007; Spigno et al., 2007; Wang et al., 2008). In another research, the maximum concentration of phenolic compounds was achieved from $M$. indica at optimal extraction time $60 \mathrm{~min}$ (Chew et al., 2011). The extended extraction duration would cause an exposure of abundant oxygen and, thus accelerate more chances for oxidation of phenolic constituents (Naczk and Shahidi, 2004; Chirinos et al., 2007) as well as the possibility of destruction by endogenous enzymes (Kuljarachanan et al., 2009). In another research, heat was found to enhance the recovery of phenolic compounds from C. asiatica at the optimal temperature $65^{\circ} \mathrm{C}(\mathrm{Chew}$ et al., 2011). Accelerated thermal treatment could improve the phenolic extraction by speeding up both diffusion coefficient and solubility of phenolic compounds in extraction solvent (Al-Farsi and Lee, 2008; Lim and Murtijaya, 2007; Silva et al., 2007). Thermal treatment was able to break down cellular components and release the bounded phenolics (Wang et al., 2008). However, harsh temperature likely decomposed the phenolics (Chan et al., 2009; Liyana-Pathirana and Shahidi, 2005).

\section{Conclusion}

Young mango leaves had various biological effects as an antioxidant and anti-inflammatory agent. It is interesting to investigate some major factors possibly affecting to the total phenolic and flavonoid content during solvent extraction. Our results revealed that ethanol concentration, extraction duration and temperature had significant influence to the total phenolic and flavonoid retention of the antioxidant stability. 


\section{Conflict of interest}

The author declared that there is no conflicts of interest in the course of conducting the research. The author has final decision regarding the manuscript and decision to submit the findings for publication.

\section{References}

Adesegun S. A. and Coker H. A. B. (2001). Plants used in traditional medicine against malaria. Nigerian Journal of Pharm., 32:50-62.

Al-Farsi, M. A. and Chang Y. L. (2007). Optimization of phenolics and dietary fibre extraction from date seeds. Food Chemistry, 108:977-985.

Chan, E. W. C.; Lim, Y. Y.; Wong, S. K.; Lim, K. K.; Tan, S. P. and Lianto, F. S. (2009). Effects of different drying methods on the antioxidant properties of leaves and tea of ginger species. Food Chemistry, 113:166-172.

Chew, K. K.; Ng, S. Y.; Thoo, Y. Y.; Khoo, M. Z.; Wan Aida W. M. and Ho, C. W. (2011). Effect of ethanol concentration, extraction time and extraction temperature on the recovery of phenolic compounds and antioxidant capacity of Mangifera indica L. extracts. International Food Research Journal, 18:571-578.

Chirinos, R.; Rogez, H.; Campos, D.; Pedreschi, R. and Larondelle, Y. (2007). Optimization of extraction conditions of antioxidant phenolic compounds from mashua (Tropaeolum tuberosum Ruíz and Pavón) tubers. Separation and Purification Technology, 55:217-225.

Dhuha Alshammaa (2016). Preliminary screening and phytochemical profile of Mangifera indica leaves extracts, cultivated in Iraq. International Journal of Current Microbiology and Applied Sciences, 5:163-173.

Donatus Ebere Okwu and Vitus Ezenagu (2008). Evaluation of the phytochemical composition of mango (Mangifera indica Linn) stem bark and leaves. Int. J. Chem. Sci., 6:705-716.

G. M. Masud Parvez (2016). Pharmacological activities of mango (Mangifera indica): A review. Journal of Pharmacognosy and Phytochemistry, 5:1-7.

Kuljarachanan, T.; Devahastin, S. and Chiewchan, N. (2009). Evolution of antioxidant compounds in lime residues during drying. Food Chemistry, 113:944-949.

Li, H.; Wong, C.; Cheng, K. and Chen, F. (2008). Antioxidant properties in vitro and total phenolic contents in methanol extracts from medicinal plants. LebensmittelWissenschaft und-Technologie, 41:385-390.
Lim, Y. Y. and Murtijaya, J. (2007). Antioxidant properties of Phyllanthus amarus extracts as affected by different drying methods. LWTFood Science and Technology, 40:1664-1669.

Liyana-Pathirana, C. and Shahidi, F. (2005). Optimization of extraction of phenolic compounds from wheat using response surface methodology. Food Chemistry, 93:47-56.

Naczk, M. and Shahidi, F. (2004). Extraction and analysis of phenolics in food. Journal of Chormatography, A 1054:95-111.

Natalia Medina Ramírez; Leticia Monteiro Farias; Francine Apolonio Santana; João Paulo Viana Leite; Maria Inês De Souza Dantas; Renata Celi Lopes Toledo; José Humberto De Queiroz; Hércia Stampini Duarte Martino and Sônia Machado Rocha Ribeiro (2016). Extraction of mangiferin and chemical characterization and sensorial analysis of teas from Mangifera indica $\mathrm{L}$. leaves of the Ubá variety. Beverages, 2:33.

Nguyen Phuoc Minh; Nguyen Hong Nga; Nguyen Thi Thuy Trang and Le Thi Them (2018). Technical factors affecting to the dried mango (Mangifera indica) leaf tea production. Journal of Global Pharma Technology, 10:181-185.

Nunez-Selles A. J. (2005). Antioxidant therapy, myth or reality? J. Braz. Chem. Soc., 16:101-108.

Olasehinde G. I.; Sholotan K. J.; Openibo J. O.; Taiwo O. S.; Bello O. A.; Ajayi J. B.; Ayepola O. O. and Ajayi A. A. (2018). Phytochemical and antimicrobial properties of Mangifera indica leaf extracts. Covenant Journal of Physical and Life Sciences, 6:55-63.

Ozsoy, N.; Can, A.; Yanardag, R. and Akev, N. (2007). Antioxidant activity of Smilax Excelsa L. leaf extracts. Food Chemistry, 110:571-583.

Pintu K. De and Arna Pal (2014). Effects of aqueous young leaves extract of Mangifera indica on gm (-) microorganisms causing gastrointestinal disorders. Asian Journal of Plant Science and Research, 4:23-27

Silva, E. M.; Rogez, H. and Larondelle, Y. (2007). Optimization of extraction of phenolics from Inga edulis leaves using response surface methodology. Separation and Purification Technology, 55:381-387.

Spigno, G.; Tramelli, L. and Faveri, D. M. D. (2007). Effects of extraction time, temperature and solvent on concentration and antioxidant activity of grape marc phenolics. Journal of Food Engineering, 81:200-208.

Wang, J.; Sun, B.; Cao, Y.; Tian, Y. and Li, X. (2008). Optimisation of ultrasound-assisted extraction of phenolic compounds from wheat bran. Food Chemistry, 106:804-810.

Citation: Minh Phuoc Nguyen (2020). Efficacy of some variables of extraction to the total phenolic and flavonoid content in young mango (Mangifera indica L.) leaf. Ann. Phytomed., 9(1):113-115. http://dx.doi.org/10.21276/ap.2020.9.1.13 